\title{
First records of myxomycetes from El Salvador
}

\author{
Rojas $\mathbf{C}^{1,2}$, Morales $\mathbf{R E}^{3}$, Calderón $\mathbf{I}^{1}$ and Clerc $\mathbf{P}^{4}$ \\ ${ }^{1}$ Instituto de Investigaciones en Ingeniería, Universidad de Costa Rica, San Pedro de Montes de Oca, 11501-2060, \\ Costa Rica. \\ ${ }^{2}$ Escuela de Ingeniería Agrícola, Universidad de Costa Rica, San Pedro de Montes de Oca, 11501-2060, Costa Rica. \\ ${ }^{3}$ Escuela de Biología, Universidad de El Salvador, Facultad Multidisciplinaria de Occidente, Santa Ana, El Salvador. \\ ${ }^{4}$ Conservatoire et Jardin Botaniques, Ch. de l'Impératrice 1, CP 60 CH-1292 Chambésy, Ville de Genève, Switzerland.
}

Rojas C, Morales RE, Calderón I, Clerc P 2013 - First records of myxomycetes from El Salvador. Mycosphere 4(6), 1042-1051, Doi 10.5943/mycosphere/4/6/2

\begin{abstract}
Myxomycetes have been studied formally in most of Central America except for El Salvador. Even though this country is the last in the region to begin an official inventory for this group of organisms, the 37 new records reported herein suggest that the myxobiota of El Salvador can be valuable for biogeographical analyses. As an example, this study reports Perichaena tessellata for the first time in the Neotropical region. Such an observation along with studies conducted in previous years in Central America show that the Mesoamerican biodiversity hotspot can provide important information to understand myxomycete dynamics in tropical areas. Additionally to the latter, during the present study a first characterization of the species of myxomycetes present in Montecristo National Park was also carried out. This is an important contribution to the biological knowledge of critical conservation areas in Central America since such park is one of the few remnants of cloud forest in El Salvador. For microbial conservation purposes, these types of rapid biodiversity assessments are imperative in understudied areas of the world such as El Salvador and necessary in forest types such as Montecristo that are threatened by climate and land use change.
\end{abstract}

Key words - biogeography - Central America - Mesoamerica - Montecristo National Park myxogastrids - species distribution.

\section{Introduction}

Myxomycetes (plasmodial slime molds or myxogastrids) are a group of ameboid protists known to occur in most terrestrial ecosystems around the world (Stephenson 2003). Once a relatively unpopular group among applied scientists, the myxomycetes have gained some popularity in recent years after the development of technologies and computer techniques based on particular characteristics of their natural history and life cycle stages (see Adamatzky \& Jones 2008, Tero et al. 2010). However, the global distribution of the majority of species as well as most aspects of their basic ecology are still in early stages of knowledge, even after global efforts such as the NSF-funded Global Biodiversity Inventory of Mycetozoans based at the University of Arkansas (see http://slimemold.uark.edu) have taken place in the recent past.

Some years ago Lado \& Wrigley de Basanta (2008) compiled a list of species known to occur across the Neotropics. The thorough examination of published scientific literature in a 180 year period provided a good start point for future surveys in the region. However, most historical 
information on Neotropical myxomycetes was found to be taxonomic in nature and it was only after the publication of Marie Farr's monographic work (Farr 1976) that various aspects of their basic ecology and ecosystem role have been addressed in a number of works across the region (see Stephenson et al. 2004, Stephenson 2011).

As part of this trend, Costa Rica became one of the best studied tropical countries in the world. Research efforts, primarily by Steven L. Stephenson, Martin Schnittler and the first author of this work (see Schnittler \& Stephenson 2000, Rojas et al. 2010a, 2012) during the last two decades have built a good base of information for complex analyses. Ironically, neighbouring countries such as Panama and Nicaragua have not had the same intensity of work during the same period of time and by 2013 only have one published work among the two since 1997 (Pando 1997). In spite of such a poor research record for myxomycetes, the best example of the lack of research in the continental Americas is represented by El Salvador. According to Lado \& Wrigley de Basanta (2008), this country was the only geopolitical jurisdiction in the Neotropics without a single scientific article on myxomycetes since 1828 .

The reasons to explain that pattern are complex and very much out of the scope of the present study. However, it is important to note that after armed conflicts and political instability during the $20^{\text {th }}$ Century and violence from the "maras" during the post-civil war era, El Salvador became one of the most violent countries in the world on the basis of intentional homicide rate (UNODC 2011). Also, the extremely high deforestation rate after 1960 has driven natural science professionals to focus biological efforts on aspects such as soil restoration and reforestation (see Secht \& Saatchi 2007), thus keeping them away from biodiversity-centered research on most taxonomic groups other than plants and vertebrates.

Given the situation of myxomycete research in El Salvador, the present study was designed with the main objective of documenting the first records of plasmodial slime molds for that country. This type of imperative research in regions of the world like Mesoamerica, a biodiversity hotspot, are relevant in a context that extends beyond the classical characterization of biodiversity since biological groups also capitalize a region in a framework of sustainability.

\section{Materials \& Methods}

The present study was carried out during the period 2012-2013 in El Salvador. The morphological concept of species has been used and the nomenclatural treatment follows Lado (2005-2013). Due to its historical inclusion on myxomycete surveys, the genus Ceratiomyxa, a deeply diverging sister group to myxogastrids (Fiore-Donno et al. 2010), was considered in the present study as well.

\section{Study areas}

Four study areas, all in the central western part of El Salvador, were selected for this study (Fig. 1). The first of these areas correspond to (A) Montecristo National Park (hereafter referred to as Montecristo); the first protected area in El Salvador. This 2000 hectare park contains a forest characterized by a dominance of the Pinus-Quercus association, ranges in elevation between 800$2400 \mathrm{~m}$ and is located $13 \mathrm{~km}$ northeast of Metapán in the Department of Santa Ana. The highest parts of this study area represent one of the few cloud forests in that part of Central America.

Within this area, four study sites were established (Fig. 2). The first site, designated as Vuelta del Guachipilín (and referred to as Guachipilín) is located at 14.38661 N, 89.39115 W and an elevation of $1463 \mathrm{~m}$. The forest patch sampled on this site is dominated by Pinus oocarpa on a flat section of the mountain. The second site, denominated Mirador del Infiernillo (Infiernillo) is located at $14.39356 \mathrm{~N}, 89.38577 \mathrm{~W}$ and an elevation of $1615 \mathrm{~m}$. This site is located next to an old landslide on the steep slope of the mountain facing the canyon of the San José river. The forest patch on this site is dominated by an assemblage of Quercus-Alnus-Pinus. The third site, on the campgrounds of Los Planes (Campgrounds) at $14.39694 \mathrm{~N}, 89.36186 \mathrm{~W}$ and an elevation of 1748 $\mathrm{m}$, is dominated by Cupressus lusitanica. This site is next to the $20 \mathrm{~km}$ road mark and is surrounded by previous agricultural lands that have been in regeneration since the establishment of 


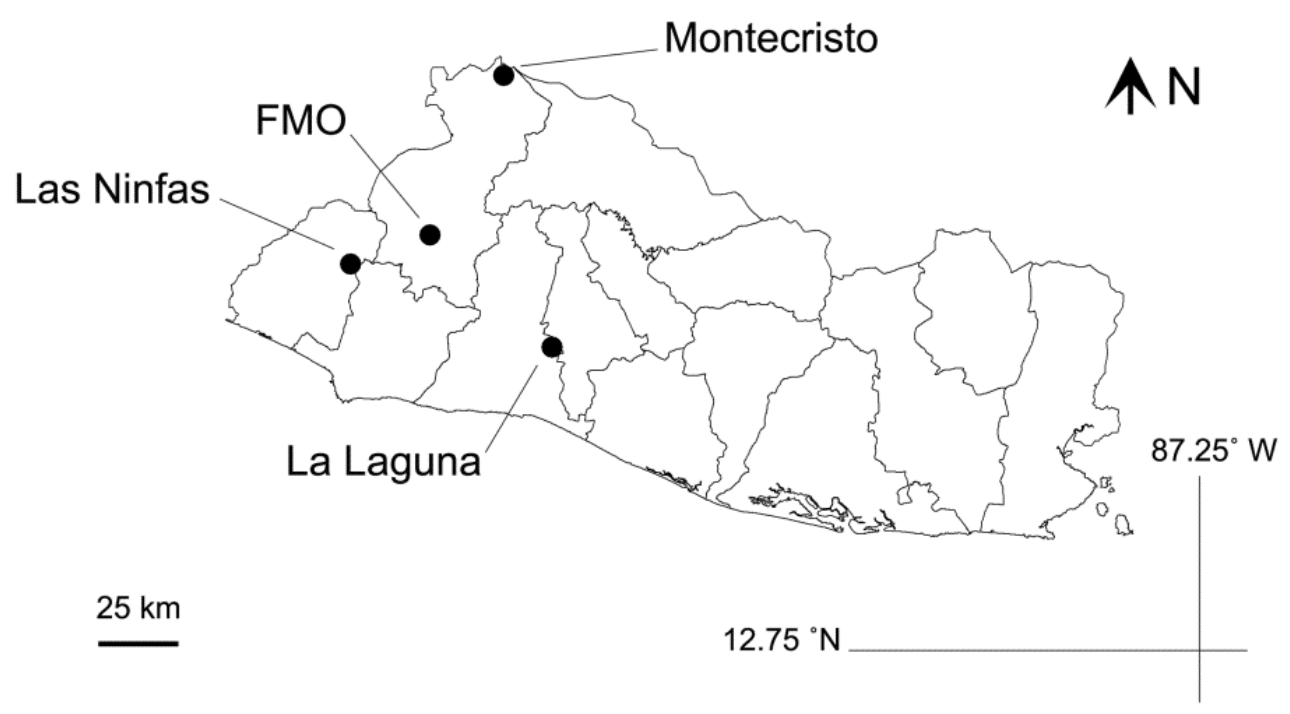

Fig. 1 - Map of El Salvador showing the four study areas of the present study. For full names and description of the areas see the Materials and Methods section.

the park. Finally, the fourth site is located on the trail to El Trifinio (Trifinio) at $14.40875 \mathrm{~N}$, $89.37206 \mathrm{~W}$ and an elevation of $2210 \mathrm{~m}$. This site corresponds to the high cloud forest areas and the vegetation does not show clear dominance of a plant species but members of the families Lauraceae, Clusiaceae, Ericaceae, Fagaceae and Clethraceae as well as ferns in such genera as Cibotia, Alsophila and Cyathea are representative.

The second area is (B) Jardín Botánico La Laguna (La Laguna); a private botanical garden. This area is located in Antiguo Cuscatlán La Libertad within the San Salvador metropolitan area, at 13.669261 N, 89.247283 W and $805 \mathrm{~m}$ of elevation. The plants in the garden represent a mixture of native and introduced elements and due to its visitation this area has dynamic changes in vegetation and structure throughout the year. La Laguna represents a forest patch within a large industrial complex and it is located in a former volcanic crater. The third area corresponds to (C) Facultad Multidisciplinaria de Occidente of the University of El Salvador in Santa Ana (FMO). This campus located at $13.970897 \mathrm{~N}, 89.575539 \mathrm{~W}$ has a three hectare forest patch surrounded by academic buildings and is located about $3.5 \mathrm{~km}$ southwest of downtown Santa Ana at $750 \mathrm{~m}$ of elevation in the Department of Santa Ana. The typical vegetation of this area is that of lowland tropical dry forests. Finally, the fourth area is (D) Laguna de las Ninfas (Las Ninfas) in Apaneca. This area is located about $4 \mathrm{~km}$ northeast of Apaneca in the Department of Ahuachapán at $13.892152 \mathrm{~N}$, $89.784095 \mathrm{~W}$ and $1650 \mathrm{~m}$ of elevation. The lagoon exists on a former crater at the Ahuachapán Volcano and the natural forest unit present in this area is represented by a premontane dry to moist transitional forest, which is highly endangered by human activity in the vicinity.

\section{Sampling}

For all areas, the opportunistic method described by Cannon \& Sutton (2004) was used to look for fruiting bodies of myxomycetes in the field during 2012 and 2013 . This method is very useful for recovering singletons and doubletons and in the case of myxomycetes, which are characterized by heterogeneous fruiting patterns, is very practical during biodiversity surveys. All records found using this method have been identified as field collections (abbreviated as FC) and have been deposited at the Museum of Natural History of El Salvador (MUHNES). In some cases, fruiting bodies have been studied in the field but no collections have been made due to collecting constraints such as lack of permits. Most specimens documented from the field were recorded on decaying wood (DW). 
In the Montecristo area, a series of 110 substrate collections for laboratory isolation of fruiting bodies was also carried out during January 2013. These collections, consisting of ground litter (GL), twigs (TW) and bark (B) were taken back to the Forest Products Laboratory of the University of Costa Rica where moist chamber cultures (abbreviated as MC) following the protocol explained by Stephenson \& Stempen (1994) were prepared. With this protocol, samples were placed on Petri dishes previously lined with filter paper. Distilled water was added to saturate the samples and after a $24 \mathrm{~h}$ period, the excess water was poured off the plate, $\mathrm{pH}$ was measured and the cultures were observed for at least three months adding water when necessary in order to maintain a moist environment within the culture. When fruiting bodies were found, these were extracted with forceps and glued into a match box. All specimens curated in this manner have been deposited at the herbarium of the University of Costa Rica (USJ) for future reference.

It is important to mention that since both collecting protocols are complementary and not mutually exclusive; the total number of species was recovered using both techniques.

\section{Species list and annotations}

The list of species presented herein includes names not previously recorded for El Salvador according to Lado \& Wrigley de Basanta (2008). The list is arranged alphabetically first by genus and then specific epithet, the names of the authors for the corresponding taxon are listed after the binomial name of the species. After this, an indication of the origin of the particular record (FC for field collections and MC for moist chamber cultures) is given, along with the number of collections, the year in which these were obtained and the collector number assigned to the specimens. The study area, abbreviated substrate type, collecting period (DP for dry and RP for rainy period) and range of $\mathrm{pH}$ values recorded for all specimens of the species in question are provided in that order as well. For the latter, only those species recorded in the laboratory have assigned $\mathrm{pH}$ values.

\section{Results}

A total of 37 species of myxomycetes were found during this study. About $48 \%$ of these were recovered using the moist chamber technique, whereas $62 \%$ were recorded from the field and approximately $14 \%$ were recorded using both collecting techniques. All of the species found in the present study represent new records for El Salvador. For the moist chamber component, the percentage of myxomycete presence in the cultures was $72 \%$ and the substrate that yielded the highest number of species was bark with about 0.6 species per moist chamber prepared. In comparison, both ground litter and twigs yielded 0.1 species per moist chamber studied.

The most commonly encountered species were Cribraria microcarpa, Perichaena depressa and Arcyria cinerea. The number of species per genus in the present study is 1.7 and $40 \%$ of the taxa recorded are related with the bright-spored clade known for myxomycetes, whereas the remaining $60 \%$ are related with the dark-spored clade. For the Montecristo study areas, where 19 species were found, substrates from Guachipilín and Infiernillo were the ones that yielded the highest number of species and records, whereas substrates from Trifinio and Campgrounds were the poorest overall.

The annotated list of new species documented herein is provided below.

\section{List of new myxomycete species for EI Salvador}

For the annotated list, the abbreviations used are: FC (field collection), MC (moist chamber collection), GL (ground litter), TW (twigs), B (bark), DW (decaying wood), DP (recorded during the dry period) and RP (recorded during the rainy period).

Arcyria afroalpina Rammeloo

MC, 2 collections, 2013, C. Rojas Ro-3225, 3268. Guachipilín and Infiernillo, on GL, DP; pH range $=5.1-6.4$. 
Arcyria cinerea (Bull.) Pers.

FC/MC, 11 collections, 2013, C. Rojas Ro-3190, 3205, 3208, 3209, 3210, 3224, 3227, 3248, 3249, 3262, 3269. Campgrounds, Guachipilín and Infiernillo, on GL and TW, RP and DP; pH range = 4.8-6.3.

Arcyria denudata (L.) Wettst.

FC, 1 collection, 2013, C. Rojas Ro-3238. Guachipilín, on DW, RP; no pH was determined.

Ceratiomyxa fruticulosa (O. F. Müll.) T. Macbr.

FC, although no actual collections were made, 2013. Guachipilín, on DW, RP; no pH was determined.

Collaria arcyrionema (Rostaf.) Nann.-Bremek. ex Lado

MC, 3 collections, 2013, C. Rojas Ro-3186, 3192, 3211. Guachipilín, on B, DP; pH range = 3.74.0 .

Comatricha laxa Rostaf.

MC, 3 collections, 2013, C. Rojas Ro-3188, 3196, 3203. Guachipilín, on GL, DP; pH range = 4.65.1 .

Comatricha nigra (Pers. ex J. F. Gmel.) J. Schröt.

MC, 1 collection, 2013, C. Rojas Ro-3230. Guachipilín, on B, DP; pH = 4.9.

Craterium concinnum Rex

MC, 4 collections, 2013, C. Rojas Ro-3181, 3184, 3221, 3229. Campgrounds, Guachipilín and Infiernillo, on GL, DP; $\mathrm{pH}$ range $=4.9-5.2$.

Cribraria argillacea (Pers. ex J. F. Gmel.) Pers.

FC, 1 collection, 2013, C. Rojas Ro-3245. Guachipilín, on DW, RP; no pH was determined.

Cribraria microcarpa (Schrad.) Pers.

MC, 13 collections, 2013, C. Rojas Ro-3182, 3185, 3195, 3197, 3199, 3200, 3213, 3215, 3218, 3220, 3222, 3223, 3228. Guachipilín, on GL and B, DP; pH range = 3.9-5.5.

Cribraria minutissima Schwein.

MC, 1 collection, 2013, C. Rojas Ro-3232. Guachipilín, on B, DP; pH = 3.8.

Cribraria tenella Schrad.

FC, 2 collections, 2013, C. Rojas Ro-3246, 3247. Guachipilín, on DW, RP; no pH was determined.

Diderma effusum (Schwein.) Morgan

FC/MC, 7 collections, 2013, C. Rojas Ro-3180, 3183, 3204, 3226, 3256, 3264, 3265. Trifinio, Campgrounds, Guachipilín and Infiernillo, on GL, RP and DP; $\mathrm{pH}$ range $=5.0-6.5$.

Didymium iridis (Ditmar) Fr.

FC, 3 collections, 2013, C. Rojas Ro-3253, 3254, 3255. Guachipilín, on GL, RP; no pH was determined.

Didymium minus (Lister) Morgan

FC, 1 collection, 2013, C. Rojas Ro-3252. Guachipilín, on GL, RP; no pH was determined.

Echinostelium minutum de Bary 
MC, although no actual collections were made, 2013. Guachipilín, on B, DP; pH range = 3.7-4.0.

Fuligo septica (L.) F. H. Wigg.

FC, no collections made, 2012. Las Ninfas, on DW, DP; no pH was measured.

Hemitrichia calyculata (Speg.) M. L. Farr

FC, 6 collections, 2013, C. Rojas Ro-3239, 3240, 3241, 3242, 3243, 3244. Guachipilín, on DW, $\mathrm{RP}$; no $\mathrm{pH}$ was determined.

Hemitrichia serpula (Scop.) Rostaf. ex Lister

FC/MC, 2 collections, 2012 and 2013, R. Morales emorales-091 and C. Rojas Ro-3187, Trifinio and FMO, on GL and DW, RP and DP; $\mathrm{pH}=5.7$.

Lamproderma arcyrioides (Sommerf.) Rostaf.

MC, 1 collection, 2013, C. Rojas Ro-3270. Guachipilín, on B, DP; pH = 4.0.

Lamproderma muscorum (Lév.) Hagelst.

FC, 2 collections, 2013, C. Rojas Ro-3233, 3234. Guachipilín, on GL, RP; no pH was determined.

Licea pusilla Schrad.

MC, 1 collection, 2013, C. Rojas Ro-3217. Guachipilín, on B, DP; pH = 4.5

Lycogala epidendrum (L.) Fr.

FC, 1 collection, 2013, C. Rojas Ro-3257. Guachipilín, on DW, RP; no pH was determined.

Lycogala exiguum Morgan

FC, 2 collections, 2013, C. Rojas Ro-3258, 3259. Guachipilín, on DW, RP; no pH was determined.

Perichaena depressa Lib.

MC, 10 collections, 2013, C. Rojas Ro-3189, 3191, 3193, 3194, 3201, 3202, 3207, 3260, 3266, 3267. Guachipilín and Infiernillo, on GL and TW, DP; pH range = 5.0-6.9.

Perichaena pedata (Lister \& G. Lister) Lister ex E. Jahn

MC, 1 collection, 2013, C. Rojas Ro-3231. Guachipilín, on GL, DP; pH = 4.9.

Perichaena tessellata G. Lister

MC, 1 collection, 2013, C. Rojas Ro-3474. Infiernillo, on GL, DP; pH = 5.0.

Physarella oblonga (Berk. \& M. A. Curtis) Morgan

FC, although no actual collections were made, 2013. La Laguna, on DW, RP, no pH was determined.

Physarum compressum Alb. \& Schwein.

FC, no collections made, 2013. La Laguna, on bracts of Heliconia inflorescences, RP; no pH was determined.

Physarum didermoides (Pers.) Rostaf.

FC, although no actual collections were made, 2013. La Laguna, on bracts of Heliconia inflorescences, RP; no $\mathrm{pH}$ was determined.

Physarum roseum Berk. \& Broome

FC, 2 collections, 2013, C. Rojas Ro-3236, 3237. Guachipilín, on GL, RP; no pH was determined. 
Physarum viride (Bull.) Pers.

FC, 1 collection, 2013, C. Rojas Ro-3235. Guachipilín, on GL, RP; no pH was determined.

Stemonaria longa (Peck) Nann.-Bremek., R. Sharma \& Y. Yamam.

FC, 1 collection, 2012, R. Morales emorales-092. FMO, on DW, RP; no pH was determined.

Stemonitis axifera (Bull.) T. Macbr.

FC/MC, 4 collections, 2013, C. Rojas Ro-3198, 3214, 3250, 3263. Guachipilín and Infiernillo, on GL and DW, RP and DP; $\mathrm{pH}=5.5$.

Stemonitis fusca Roth

MC, 1 collection, 2013, C. Rojas Ro-3219. Guachipilín, on GL, DP; pH = 4.9.

Stemonitopsis hyperopta (Meyl.) Nann.-Bremek.

FC, 1 collection, 2013, C. Rojas Ro-3251. Guachipilín, on DW, RP; no pH was determined.

Willkommlangea reticulata (Alb. \& Schwein.) Kuntze

MC, 1 collection, 2013, C. Rojas Ro-3206. Infiernillo, on GL, DP; pH = 5.1.

\section{Discussion}

The first published list of myxomycetes for El Salvador presented herein is a remarkable effort considering the lack of specialists on the group in that country and the legal restrictions that foreigners have when conducting biological research in Salvadorian jurisdictions. In spite of that, the present effort positions El Salvador on the myxomycete research map for the first time and provides scientific elements to alleviate the disparity on biological research among Central American countries.

All species recorded during the present study have been reported for the Central American region in previous studies (see Lado \& Wrigley de Basanta 2008). However, for a first and geographically limited survey in El Salvador, the present study shows interesting results that definitely warrant further investigation. For example, the ratio between species of plants and species of myxomycetes for this country is at most 92:1 based on a value of 3411 plant species (Gallo 2005) and the myxomycete diversity results from this study. In the case of Costa Rica, a very well studied country in the same region, the same ratio is 55:1 based on a value of 11451 plant species (Obando 2007) and 208 species of myxomycetes (Rojas et al. 2010a). These values seem to suggest that the relation between Costa Rican and Salvadorian myxomycete diversity is about 1.7:1 when the calculation is normalized using plant species as a parameter.

It is clear that such a result is a simple mathematical artifact produced by the low number of known myxomycetes for El Salvador. Given the geoclimatic conditions of this country, the number of myxomycete species should be higher based on results from previous surveys in other dry areas in the region (e.g. Estrada-Torres et al. 2009). For instance, the Guanacaste province in Costa Rica, an area with similar climate to El Salvador but with about half the size of the latter has at least 127 myxomycete species. If a similar number of species were known for El Salvador, then the plant to myxomycete ratio would be $34: 1$, indicating that the relation between Costa Rican and Salvadorian myxomycete diversity would be 1:1.6 when normalized by the number of plant species. This example is obviously just an indication that the myxomycete biota of El Salvador may be comparatively richer than that of neighbouring countries and unless real data are used, it is speculative. However, it illustrates the need for more research in El Salvador and for regional-based surveys in biodiversity hotspots such as Mesoamerica, which like other equivalent areas is particularly heterogeneous in terms of potential niches for species.

The records of $A$. cinerea, C. fruticulosa, H. calyculata, L. epidendrum and S. axifera are not surprising from a distributional standpoint. These five species are broadly distributed along the 
Neotropics (Lado \& Wrigley de Basanta 2008). However, it is interesting to note that during the present survey species such as $C$. concinnum, Cr. argillacea, L. muscorum, $P$. roseum and $W$. reticulata were recorded as well. The latter species are not particularly common in myxomycete surveys in the Central American region and in fact probably represent the only records for those species besides the collections from Costa Rica. In spite of the latter, those species have also been found in the Caribbean and South America, which would also indicate that their distributional range is not limited to the Central American forests. As such, it simply appears that undersampling in most Neotropical areas may be the determining factor for their known distribution at this point.

A particular case is the record of Perichaena tessellata found on ground litter from Infiernillo. This species is very rare worldwide and based on published information appears to be the first record of the species in the Neotropical region (Lado \& Wrigley de Basanta 2008). The area where the substrate came from is dominated by Quercus species; however, the presence of Alnus and less commonly Liquidambar shape a particular habitat that is difficult to find in other areas on the pacific coast of Central America. A particular analysis of the presence of the record in the Montecristo area warrants further research but it provides data to support the idea that this area represents an interesting biogeographical locality in Central America.

It is interesting to note that the number of species per genus in the present study is 1.7 . For Costa Rica this value is a high as 5.8 (Rojas et al. 2010a), for Thailand is 4.4 (Ko Ko et al. 2010) and for tropical areas in India is higher than 3.0 (Stephenson et al. 1993). However, all those countries have wet areas with a vegetation type that is absent in the pacific coast of Central America where El Salvador is located. In spite of that, it seems that the intrageneric diversity in the latter country has not reached a value that would suit a tropical country and may show the limited extent of the present survey to characterize the myxomycete biota of such country.

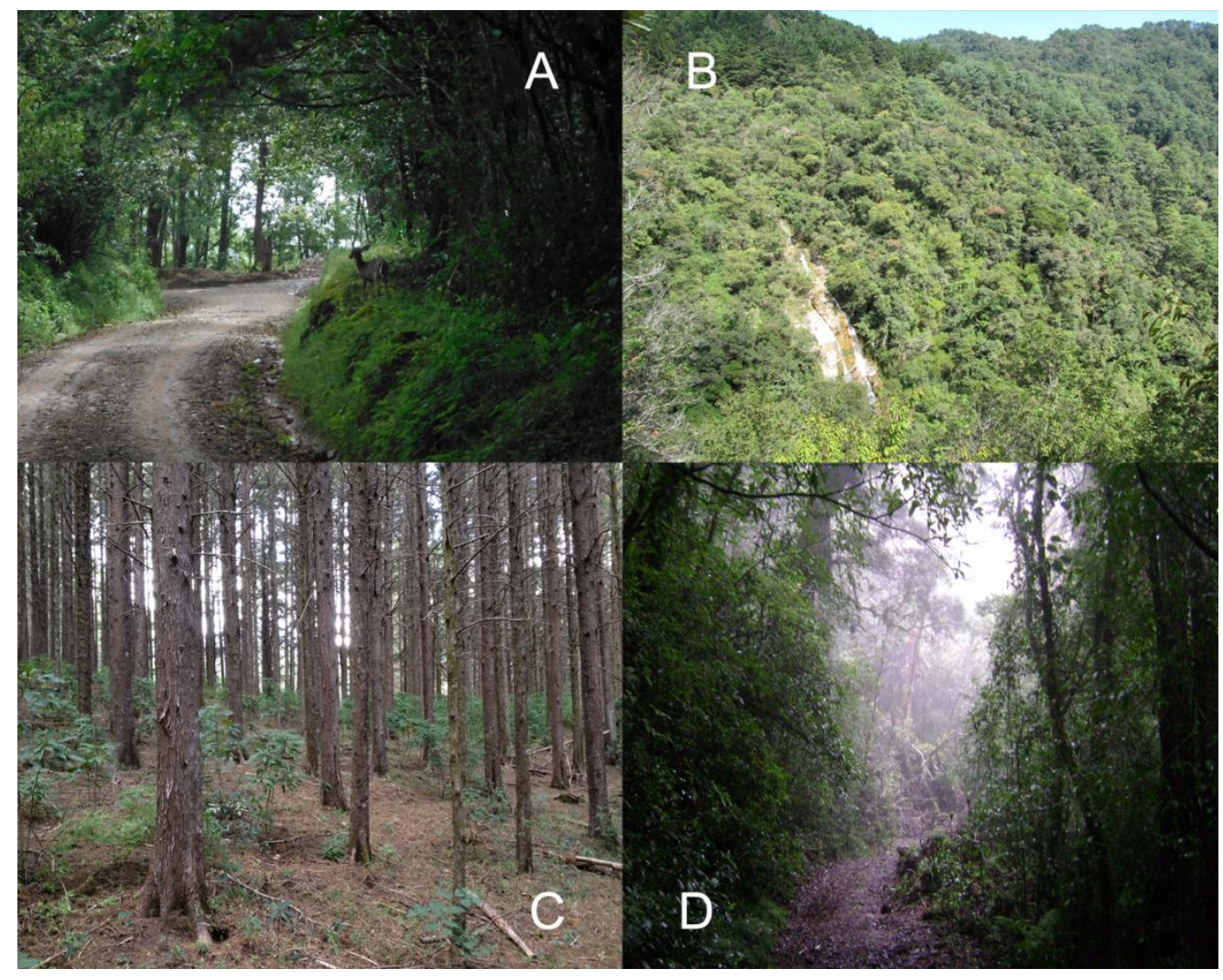

Fig. 2 - The four study sites surveyed in Montecristo National Park as part of the present study. A. Guachipilín; B. Infiernillo; C. Los Planes y D. Trifinio. For full names and description of the areas see the Materials \& Methods section. 
The results from the Montecristo National Park are expected based on similar surveys in high-elevation areas of other Central American countries (see Rojas \& Stephenson 2007, Rojas et al. 2010b). Interestingly, species of the genera Trichia and Lamproderma, relatively common in the latter mountains, were not recorded in Montecristo or similar surveyed areas in Guatemala. In this sense, the phenology of the species would be an important factor to consider in the distributional analysis. However, as noted by Rojas et al. (2011), forest structure also seems to be a key factor explaining the presence of Neotropical myxomycetes in field conditions. High elevation areas in Costa Rica have a very different forest structure due to the presence of southern understory elements such as Chusquea, which are absent in the more typical Pinus-Quercus forests found in El Salvador and Guatemala at similar elevations. At this point, it would be speculative to explain the difference in species assemblages in any way, but the observation certainly works out as a starting point for future research on the subject.

In spite of any differences, the three most common species recorded during the present survey have also been common in other studies on mountains in the Central American region. Also, the percentage of myxomycete presence in moist chambers and the distribution of species between the two spore clades are similar to what has been found in Costa Rica as a point of comparison. However, a better analysis can be performed once more ecosystem types in El Salvador are studied. A particularly interesting point is that both Physarum compressum and $P$. didermoides were found on bracts of Heliconia plants. This phenomenon has already been described by Schnittler \& Stephenson (2002), but it has been observed previously in Central America only for Costa Rica and now for El Salvador.

In brief, the present study expands our knowledge on the distribution of myxomycetes within a biodiversity hotspot and represents a starting point for future research on the group in El Salvador. This effort is an attempt to gain information on the dynamics of tropical forests and provides information about a taxonomic group that occurs in the Montecristo National Park, a protected area with a number of anthropogenic threats. Given the fact that baseline data are always needed for monitoring purposes, this study is also a contribution to the conservation of intermediate to high elevation Neotropical forests.

\section{Acknowledgements}

This study was primarily funded by Vicerrectoría de Investigación of the University of Costa Rica through the research code 731-B2-224. Portions of the field work were supported by the Conservatoire et Jardin botaniques of Geneva through a grant to P. Clerc. Gratitude is extended to the Ministry of Environment and Natural Resources of El Salvador for granting permission to work in protected areas; to Maritza Guido and the personnel of the Montecristo National Park for logistic aid, to Steven L. Stephenson for help with the identification of some records and to Erick Calvo and Stephanie Sommerville for their valuable help in the laboratory.

\section{References}

Adamatzky A, Jones J. 2008 - Towards Physarum Robots: Computing and Manipulating on Water Surface. Journal of Bionic Engineering 5, 348-357.

Cannon P, Sutton B 2004 - Microfungi on wood and plant debris. In: Biodiversity of Fungi: Inventory and Monitoring Methods (eds Mueller G, Bills G, Foster M). Elsevier Academic Press. Burlington, Massachusetts, 217-239.

Estrada-Torres A, Wrigley de Basanta D, Conde E, Lado C. 2009 - Myxomycetes associated with dryland ecosystems of the Tehuacán-Cuicatlán Valley Biosphere Reserve, Mexico. Fungal Diversity 36, 17-56.

Farr ML 1976 - Flora Neotropica Monograph No. 16. (Myxomycetes). The New York Botanical Garden, New York.

Fiore-Donno AM, Nikolaev SI, Nelson M, Pawlowski J, Cavalier-Smith T, Baldauf S. 2010 - Deep Phylogeny and Evolution of Slime Moulds (Mycetozoa). Protist 161: 55-70. 
Gallo M 2005 - Estado del conocimiento de la biodiversidad en El Salvador. INBio, Santo Domingo de Heredia, Costa Rica.

Ko Ko T, Hanh T, Stephenson SL, Mitchell DW, Rojas C, Hyde KD, Lumyong S, Bahkali AH. 2010 - Myxomycetes of Thailand. Sydowia 62, 243-260.

Lado C 2005-2013 - An on line nomenclatural information system of Eumycetozoa. Real Jardín Botánico de Madrid, Spain. http://www.nomen.eumycetozoa.com (accessed 21 August 2013).

Lado C, Wrigley de Basanta D. 2008 - A Review of Neotropical Myxomycetes (1828-2008). Anales del Jardín Botánico de Madrid 65, 211-254.

Obando V 2007 - Biodiversidad de Costa Rica en Cifras. INBio, Santo Domingo de Heredia, Costa Rica.

Pando F 1997 - Catálogo preliminar de los Mixomicetes del Parque Nacional de Coiba (Panamá). In: Flora y fauna del Parque Nacional de Coiba (Panamá) (ed. Castroviejo S). Agencia Española de Cooperación Internacional, Madrid, 191-204.

Rojas C, Stephenson SL. 2007 - Distribution and ecology of myxomycetes in the high-elevation oak forests of Cerro Bellavista, Costa Rica. Mycologia 99, 534-543.

Rojas C, Schnittler M, Stephenson SL. 2010a - A review of the Costa Rican myxomycetes (Amebozoa). Brenesia 73/74, 39-57.

Rojas C, Stephenson SL, Estrada-Torres A, Valverde R, Morales O. 2010b - New records of myxomycetes from high-elevation areas of Mexico and Guatemala. Mycosphere 1,73-82.

Rojas C, Stephenson SL, Huxel G. 2011 - Macroecology of high-elevation myxomycete assemblages in the northern Neotropics. Mycological Progress 10, 423-437.

Rojas C, Stephenson SL, Valverde R, Estrada-Torres A. 2012 - A biogeographical evaluation of high-elevation myxomycete assemblages in the northern Neotropics. Fungal Ecology 5, 99113.

Schnittler M, Stephenson SL. 2000 - Myxomycete biodiversity in four different forest types in Costa Rica. Mycologia 92, 626-637.

Schnittler M, Stephenson SL. 2002 - Inflorescences of Neotropical herbs as a newly discovered microhabitat for myxomycetes. Mycologia 94, 6-20.

Secht SB, Saatchi SS. 2007 - Globalization and Forest Resurgence: Changes in Forest Cover in El Salvador. BioScience 57, 663-672.

Stephenson SL 2003 - Fungi of New Zealand Vol. 3: Myxomycetes of New Zealand. Fungal Diversity Research Series 11, 1-238.

Stephenson SL. 2011 - From morphological to molecular: studies of myxomycetes since the publication of the Martin and Alexopoulos (1969) monograph. Fungal Diversity 50, 21-34.

Stephenson SL, Kalyanasundaram I, Lakhanpal T. 1993 - A comparative biogeographical study of Myxomycetes in the mid-Appalachians of eastern North America and two regions of India. Journal of Biogeography 20, 645-657.

Stephenson SL, Stempen H 1994 - Myxomycetes: a handbook of slimemolds. Timber Press, Oregon.

Stephenson SL, Schnittler M, Lado C, Estrada-Torres A, Wrigley de Basanta D, Landolt J, Novozhilov Y, Clark J, Moore D, Spiegel F. 2004 - Studies of Neotropical Myxomycetes. Systematics and Geography of Plants 74, 87-108.

Tero A, Takagi S Saigusa T, Ito K, Bebber DI, Fricker MD, Yumiki K, Kobayashi R, Nakagaki T. 2010 - Rules for Biologically Inspired Adaptive Network Design. Science 327, 439-442.

UNODC 2011 - 2011 Global study on homicide. United Nations Office on Drugs and Crime, Vienna. 